\title{
Preferencias adaptativas: un obstáculo pendiente para la renta básica
}

\author{
PEDRO JESÚS PÉREZ ZAFRILLA* \\ Universitat de València (España) \\ P.Jesus.Perez@uv.es
}

\begin{abstract}
Resumen renta básica pueda empoderar también a los más pobres. cia.

\section{Adaptive preferences: \\ a remaining obstacle for basic income}

La renta básica proporciona a la ciudadanía una autonomía económica que se traduce en una libertad real para conducir sus vidas. Sin embargo, en este artículo defiendo que la renta básica no sería efectiva en situaciones de pobreza donde se generan preferencias adaptativas en las personas. Para mostrarlo analizaré las bases psicológicas del comportamiento de personas con preferencias adaptativas. A continuación, abordaré qué estrategias son las indicadas para revertir la situación de preferencias adaptativas. Implementar estas políticas permitirá que la

Palabras clave: Renta básica, preferencias adaptativas, pobreza, exclusión, agen-

\begin{abstract}
Basic income provides citizenship an economic autonomy which is translated in a real liberty to drive their lives. However, in this article I aim to analyse why basic income would not be effective in situations of poverty in which people have "adaptive preferences". I will analyse the psychological bases of the behaviour of persons with adaptive preferences. Then, I will study which strategies are more proper to reverse that situation. This would allow understanding how basic income could empower to the poorest too.
\end{abstract}

Key words: Basic income, adaptive preferences, poverty, exclusion, agency.

Doctor en Filosofía por la Universitat de València. Profesor Titular de Filosofía Política en la Universitat de València. Es autor de La democracia en cuestión. Los ciudadanos demandan una política diferente (2017).

Este estudio se inserta en el Proyecto de Investigación Científica y Desarrollo Tecnológico "Neuroeducación moral, democracia deliberativa y políticas de desarrollo humano sostenible” (FFI2016-76753-C2-1-P), financiado por el Ministerio de Ciencia, Innovación y Universidades. 


\section{INTRODUCCIÓN}

En las actuales sociedades con Estado del bienestar ha cobrado fuerza una propuesta económica conocida como la renta básica. Entre los objetivos de dicha medida está procurar una redistribución de recursos y acabar con la pobreza. Según sus defensores, la renta básica podría contribuir a resolver el problema de la pobreza mejor que los planes existentes de subsidios condicionados. Esto es así porque proporcionaría una red de seguridad económica que otorgaría a la persona una libertad efectiva para sacar su vida adelante realizando un proyecto vital que pueda ser libremente elegido y no impuesto por las circunstancias existentes. Más concretamente, autores como Daniel Raventós señalan que la renta básica sería de especial utilidad en situaciones de pobreza en que se generan preferencias adaptativas entre las personas. Aquí la renta básica contribuye a que la persona pueda calibrar mejor las preferencias generadas en ella por el entorno (Raventós, 1999: 46). De esta forma podría abandonar su situación de pobreza e integrarse en la sociedad.

Sin embargo, frente a lo mantenido por Raventós, en este trabajo deseo mostrar que la renta básica encuentra un obstáculo para realizar su papel emancipador precisamente en las situaciones donde se generan preferencias adaptativas. Estos son, de manera general, contextos de vulnerabilidad como la exclusión social, la drogadicción o el maltrato. En mi opinión, la renta básica no responde de manera adecuada a la situación de preferencias adaptativas, y no logra por ello cumplir su objetivo de que las personas puedan salir de la pobreza. Para mostrarlo, analizaré las bases psicológicas del comportamiento de las personas con preferencias adaptativas y por qué ese comportamiento les impide aprovecharse del potencial que la renta básica tiene como liberador de la pobreza.

El artículo comienza con una introducción explicativa de la idea de renta básica y de su actualidad en el ámbito teórico. En las siguientes secciones se desgranan los supuestos psicológicos que caracterizan el comportamiento de las personas que viven en contextos de preferencias adaptativas. En concreto, se abordará el modelo de racionalidad que subyace a las preferencias adaptativas, las bases neuropsicológicas de dicho fenómeno, el desarrollo de las capacidades de los sujetos que viven en situaciones de preferencias adaptativas y la influencia que el entorno ejerce en la capacitación de las personas. Estos supuestos pueden explicar, en mi opinión, la incapacidad de los sujetos para hacer un uso eficaz de la renta básica en esos contextos de necesidad. Sobre esta base podremos, en una última sección del artículo, presentar qué políticas es necesario implementar para que los sujetos abandonen la situación de preferencias adaptativas y puedan ser capaces de emplear la renta básica de un modo efectivo. 


\section{LA RENTA BÁSICA}

La renta básica consiste en "un ingreso pagado por el Estado a cada miembro de pleno derecho de la sociedad, incluso si no quieren trabajar de forma remunerada, sin tomar en consideración si es rico o pobre, o, dicho de otra manera, independientemente de cuáles puedan ser las otras posibles fuentes de renta, y sin importar con quien conviva" (Raventós, 2007: 22). Es decir, constituye un pago monetario a cargo del Estado, de carácter personal (no por unidad familiar), realizado de manera periódica

y con carácter general: se dirige a todos los miembros de la comunidad, mayores o menores de edad, siempre que cuenten con la ciudadanía o al menos un mínimo de periodo de residencia en el país. Además, a diferencia de los actuales subsidios sociales, la renta básica cuenta con un carácter de incondicionalidad: se trataría de un derecho y se pagaría a todas las personas con independencia de sus circunstancias personales (condiciones de salud, nivel de renta o disposición a trabajar).

A pesar de que el objetivo de sus defensores es que la cantidad asignada fuera la más alta posible, se entiende que se trataría de un ingreso modesto, aunque suficiente, para cubrir las necesidades básicas de la vida (Pinilla, 2004). Por otro lado, si bien de forma general la entidad pensada como proveedora de la medida suele ser el Estado o una entidad subestatal, también hay propuestas de renta básica a nivel supranacional (Van Parijs \& Vanderborght, 2010), referidas por ejemplo en la Unión Europea (Van Parijs \&Yannick, 2001) o incluso una renta básica a nivel global pagada a través de un impuesto progresivo mundial (Pogge, 1994; Frankman, 2004).

Aunque la renta básica es una propuesta que goza de actualidad, sus orígenes se remontan siglos atrás. Su primer referente es el misthón, la asignación monetaria que otorgaba a los pobres la capacidad de participar en las asambleas y tribunales populares y que fue introducida tras las reformas democráticas de Efialtes en la Atenas clásica allá por el 460 a.C. (Doménech, 2003). Tras esta iniciativa, otros muchos autores han propuesto medidas similares a la renta básica entre los siglos XVIII y XX (Van Parijs, 2002: 48; Rallo, 2015: 25-28). Los autores más característicos han sido los siguientes: Thomas Paine y Thomas Spence en el s.XVIII; en siglo XIX Charles Fourier, Joseph Chartier, Agathon de Potter o Mill en Principios de Economía Política. Ya en el siglo XX, en el periodo de entreguerras, encontramos a académicos como G.D.H. Cole y James Meade proponiendo la instauración de un "dividendo social" que inspiró la propuesta del "impuesto negativo sobre la renta" del liberal Milton Friedman. Por último, también Martin Luther King hizo su propuesta de renta básica (Rallo, 2015: 27). 
Pero ha sido en las últimas décadas cuando la propuesta de renta básica ha cobrado mayor presencia en el ámbito académico, sobre todo entre las corrientes republicana y socialdemócrata. Sus máximos representantes serán respectivamente Daniel Raventós y Philippe Van Parijs. Pero también pueden señalarse defensores del liberalismo que apuestan por formas de renta básica como Hillel Steiner o el ya citado Milton Friedman, figura destacada de la Escuela de Chicago. Incluso en el libertarismo hay firmes defensores de la renta básica, como Matt Zwolinski (2015), aunque sus tesis han sido también criticadas desde posiciones liberales (Rallo, 2017). Así pues, podemos considerar hoy la renta básica como una medida trasversal que encuentra defensores (y también críticos) en diversas corrientes de pensamiento.

Más allá de las diferencias entre las corrientes teóricas que apoyan la renta básica, todas ellas comparten un elemento: la renta básica es heredera en buena medida de la idea que ha recorrido el pensamiento político desde el mundo antiguo hasta las revoluciones proletarias del s.XIX: ciudadano es aquel que goza de autosuficiencia económica gracias a la posesión de una cantidad de propiedad suficiente. Como señala Cortina, "quien es autosuficiente en lo económico puede permitirse no ser vasallo en lo político" (2001), en tanto que su voto no estaría sometido a la decisión de terceras personas. En este sentido, las propuestas de renta básica, tanto la republicana como la socialdemócrata, van más allá del modelo liberal de libertad formal de igualdad de derechos y oportunidades y proponen instaurar una libertad real que pueda garantizar a las personas la posibilidad de llevar a cabo sus planes de vida. Para ello se propone la introducción de la renta básica. Esta medida garantizaría a los ciudadanos quedar libres de la pobreza y emprender un plan de vida en el que se encontraran autorrealizados (Cortina, 2017: 144).

Hecha esta presentación inicial, en las siguientes páginas pretendo mostrar por qué la renta básica resulta de escasa utilidad en contextos de exclusión. Estos son ámbitos donde proliferan las preferencias adaptativas. Basaré mi análisis en los elementos psicológicos que aparecen en el comportamiento de personas con preferencias adaptativas. Ello nos permitirá finalmente conocer mejor qué reformas son necesarias para que las personas en condiciones de pobreza puedan aprovechar el potencial emancipador de la renta básica.

\section{LA RACIONALIDAD Y LAS PREFERENCIAS ADAPTATIVAS}

Hemos de partir de la concepción de la racionalidad que subyace a las propuestas de renta básica. Éstas presuponen el modelo de racionalidad establecido por Sibley (1953: 554-560) y que recogerá Rawls (1996: 80; 
2002: 371): la persona racional es aquella capaz de fijarse unos fines propios, de ordenarlos según un orden de prioridad y de elegir los medios conducentes a su consecución. Estas acciones se llevarán a cabo mediante lo que Rawls denomina "racionalidad deliberativa", esto es, la deliberación aplicada a la elección de los fines más provechosos y los medios más eficaces para dichos fines propuestos. ${ }^{1}$ Así lo expresa Rawls a propósito de la idea de la bondad como racionalidad: "partimos del supuesto de que todos los ciudadanos tienen un plan racional de vida cuya realización requiere aproximadamente del mismo tipo de bienes primarios" (Rawls, 1996: 214 n.8).

Un elemento central aquí es que, para los teóricos de la renta básica, la persona está capacitada a priori para elegir un plan de vida propio, y de luchar por conseguirlo. La única limitación de las personas es la carencia de una base económica que permita ejercer esa capacidad de forma efectiva, ya que su voluntad se encuentra sometida a la influencia arbitraria de personas colocadas en una situación más poderosa (Van Parijs, 1996; Raventós, 2007). Estos autores propondrán la renta básica como la medida que proporciona un colchón de seguridad con el que los sujetos pueden tener una libertad real de elegir entre distintos planes de vida y lograr su realización. Pero, sobre todo, las propuestas de la renta básica presuponen otra idea clave: sean cuales sean los planes de vida elegidos, todos tendrán un denominador común: consisten en aspirar a tener una vida mejor. Así dice Pinilla: "Casi todo el mundo quiere siempre más de lo que ya tiene" (Pinilla, 2004: 101). También, como señala Raventós (2007: 87) las personas se fijan de forma general objetivos de vida que trascienden su situación actual.

Pues bien, mi tesis en este punto es que ambos supuestos en los que se apoya la propuesta de la renta básica se desmoronan en los contextos donde aparecen preferencias adaptativas. Por un lado, los sujetos que muestran preferencias adaptativas no poseen un comportamiento racional, sino irracional, dominado por un conjunto de sesgos cognitivos. Por otro lado, su plan de vida, lejos de aspirar a una vida mejor, queda reducido a la aceptación de la situación de pobreza o exclusión en que se encuentra la persona (Cortina, 2013: 105). Es decir, en lugar de elegir un fin y transformar el medio en que vive para lograr aquél, la persona con preferencias adaptativas se limita a aceptar como buena la situación de miseria en que se encuentra y ello bloquea la capacidad racional de proyectar planes de vida con los que realizarse y abandonar su situación de necesidad.

Esta no sería una racionalidad medios-fines de corte egoísta, pues los fines que se marca el individuo pueden no ser beneficiosos para él estrictamente, sino para la comunidad a la que pertenece, por ejemplo. 
El fenómeno de las preferencias adaptativas ha sido estudiado principalmente por Gustavo Pereira y su equipo de investigación en la Universidad de la República de Uruguay, así como desde la Escuela de Valencia (Conill, 2004; Cortina, 2013), existiendo una colaboración fluida entre ambos grupos (Cortina \& Pereira, 2009). También Martha Nussbaum ha reflexionado sobre este concepto, centrándose sobre su incidencia en las mujeres (Nussbaum, 2002: 161-227). Pero con anterioridad el fenómeno de las preferencias adaptativas fue apuntado por John Elster en su obra Uvas amargas, cuyo nombre evoca la conocida fábula de la zorra y las uvas de Esopo. Esta fábula refleja cómo las personas, ante momentos de frustración por no poder conseguir sus objetivos, reaccionan rechazando los objetivos inicialmente fijados y degradando sus voliciones a lo que en realidad pueden conseguir (Esopo, 2000: 20). De esta forma es como las personas consiguen reducir esa frustración sufrida.

Para conocer el fenómeno de las preferencias adaptativas hemos de partir de las revelaciones producidas por la neuropsicología en las últimas décadas. Estos estudios (Haidt, 2001: 819-821) muestran que nuestra mente necesita estar serena y mantener una coherencia entre nuestras actitudes y nuestro conocimiento de la realidad. Cuando surge una incoherencia entre ambas el sujeto se enfrenta a una disonancia cognitiva. En esas situaciones nuestra mente siente frustración e inmediatamente genera una reacción de signo contrario dirigida a reducir o eliminar esa incomodidad (Pereira, 2007: 144-147). Esa reacción puede cobrar dos formas distintas que podemos mostrar con el siguiente ejemplo.

Un fumador se enfrenta a una disonancia cognitiva cuando conoce que fumar conlleva graves daños sobre la salud. La disonancia se produce porque la información de que la adicción al tabaco produce cáncer choca con la disposición a fumar propia del fumador. En esta situación el fumador puede reaccionar de dos formas distintas. Puede asimilar esa información e intentar modificar sus acciones con el objetivo de dejar de fumar. $\mathrm{O}$, por el contrario, puede restar peso a las informaciones médicas que contravienen su disposición a fumar o familiarizarse con otros estudios que mitigan los efectos perniciosos del tabaco. La diferencia entre ambas reacciones es esencial. Mientras la primera es consciente y racional, la segunda es no consciente e irracional. Efectivamente, ésta última es el resultado del conocido "sesgo de confirmación": las personas tienden a conceder mayor credibilidad a informaciones que concuerdan con sus creencias previas sobre un asunto o con sus actitudes sobre el mismo y a restar peso a las informaciones que chocan con su opinión sobre el caso (Haidt, 2001: 
821; Mercier \& Sperber, 2011: 63-64)². Este sesgo permite mantener nuestra mente tranquila y la coherencia entre informaciones sobre la realidad y nuestras actitudes. Pues bien, ambos tipos de reacciones psicológicas serán claves para entender el fenómeno de las preferencias adaptativas.

\section{LA PLANIFICACIÓN DEL CARÁCTER Y LAS PREFERENCIAS ADAPTATIVAS}

Ciertamente, la adaptación de los deseos a las posibilidades reales que se tienen es un fenómeno completamente normal al que cualquier persona se enfrenta en más de una ocasión a lo largo de su vida. El problema reside en el proceso psicológico por el que esa adecuación se produce como respuesta a la disonancia surgida por la constatación de que no es posible cumplir nuestros deseos iniciales. John Elster (1988) señala dos formas de adecuación de los deseos y reducción de la disonancia: una sería la "planificación de carácter" y otra las "preferencias adaptativas".

La planificación del carácter se lleva a cabo de una forma racional. Consiste en asimilar la información disonante con nuestros deseos iniciales y en adecuar nuestros deseos a objetivos factibles de un modo intencional, consciente y racional en esta nueva situación. Ello permite que la persona pueda proyectar otros objetivos más realistas, evaluar las distintas alternativas posibles para lograrlos y elegir la mejor entre ellas.

A diferencia de la planificación del carácter, las preferencias adaptativas responden a la disonancia cognitiva mediante la degradación no consciente de la alternativa deseada y aceptando de forma irracional como buena una situación a la que el sujeto se ha acabado acostumbrando. Ello hará en este último caso que se congele todo deseo de mejorar esa situación sobrevenida. Por ese motivo, las preferencias adaptativas suponen, como el propio Elster señala, una subversión de la racionalidad. Como vimos, el comportamiento racional implica el establecimiento de unos fines y la elección de los medios que permitan conseguirlos. En cambio, las preferencias adaptativas subvierten ese mecanismo y conducen al sujeto a conformarse irracionalmente con lo que tiene y, más aún, lo incapacitan también para transformar su situación ${ }^{3}$.

2 Sobre la irracionalidad del sesgo de confirmación puede consultarse Pérez Zafrilla (2013; 2016).

3 Dicho comportamiento ejemplifica otro sesgo cognitivo estudiado ampliamente en el ámbito de la psicología: el sesgo de razonamiento motivado. Cierta psicología moral reciente defiende que el razonamiento no constituye un proceso cognitivo dirigido a la formación de un juicio neutral sobre un asunto (Kunda, 1990: 480-498; Haidt, 2001: 821; Haidt \& Bjorklund, 2008: 820; Mercier \& Sperber, 2011: 66). En realidad, los sujetos razonan desde una posición predeterminada por nuestros deseos y actitudes, de tal forma que el razonamiento termina por concluir aquello que el sujeto deseaba o prefería en un 
Ahora bien, ¿y por qué en la situación de preferencias adaptativas los sujetos se encuentran incapacitados para mejorar su situación? Esto es debido a que las preferencias adaptativas surgen (de manera general) en contextos de pobreza, definida en términos de desarrollo de las capacidades. Allí las personas no tienen garantizadas unas oportunidades básicas como la comida, la educación, la sanidad, una vivienda o la seguridad en el empleo (Pedrajas, 2006: 288). Esa vida por debajo de un umbral mínimo de capacidades hace que los sujetos tengan mermada su autonomía. Dicho en la terminología de Sen, el sujeto tiene socavada su libertad de agencia, esto es, su habilidad para fijarse fines y llevarlos adelante. Ello le impide transformar en bienestar los medios con los que cuenta como el resto de personas. Por ello, como veremos a continuación, la falta de libertad de agencia hará que los sujetos se fijen planes de vida más limitados, llegando a conformarse con la situación de miseria en que se encuentran (Sen, 1995: 46 y 2000: 103; Burdin, Leites, Salas \& Vigorito, 2009: 163-192). En consecuencia, la falta de libertad de agencia en esos contextos de pobreza lleva a la subversión de la racionalidad señalada por Elster: el sujeto, en lugar de proyectar unos fines y buscar unos medios que le permitan conseguirlos, se limita a racionalizar formas de encontrar aceptable la situación de pobreza en que se encuentra.

\section{LAS “CREENCIAS CAPARAZÓN”}

Ligado al fenómeno de las preferencias adaptativas existe otro modo en que las personas pueden eliminar la disonancia cognitiva. Los sujetos que conviven en contextos de maltrato o pobreza acaban por adoptar creencias que les lleven a aceptar su situación (Pereira, 2009: 57-76). Claras muestras de ello serían la incorporación de la creencia de la inutilidad de los procesos educativos formales para la capacitación de los hijos, o también la creencia que adquiere la mujer maltratada de que el marido maltratador en el fondo la quiere. Esas creencias actuarán al modo de caparazón que impidan asimilar informaciones relativas al poder de la educación como elemento capacitador de la persona o las relativas a las soluciones que hay para salir del maltrato.

¿Y cómo se adquieren ese tipo de "creencias caparazón"? Podemos señalar dos medios: uno son las propias experiencias de frustración en la consecución de los objetivos marcados inicialmente por el sujeto para salir de la pobreza. Eso le lleva, como vimos, a degradar sus objetivos y a asimilar su situación de pobreza como buena, eliminando todo deseo de salir

principio. En el caso de las preferencias adaptativas el razonamiento está guiado por el deseo de calmar la disonancia cognitiva. 
de ella (Pereira, 2004: 78). Pero la otra forma de adquirir esas creencias caparazón es la propia convivencia en contextos de pobreza y miseria. La gente que vive en esos entornos aprende desde niño qué cosas son posibles de alcanzar y qué objetivos puede marcarse en la vida. Esta situación es explicada de manera nítida por Evans con su concepto de las "capacidades colectivas" (Evans, 2002: 54-60).

Defiende Evans que los grupos en los que conviven las personas tienen no sólo un valor inherente en la formación de la identidad de sus miembros, sino también en la articulación de las metas que merecen ser perseguidas. Esto es así porque los entornos y colectivos de interacción de los individuos son "los instrumentos para el desarrollo de las capacidades de los sujetos que los componen" (Reyes Morel, 2009: 42). Aquí hemos de incluir tanto las comunidades voluntarias (partidos, sindicatos, ONGs, iglesias, etc...) como, de una manera especial, las involuntarias (familia, etnia, raza, casta), pues éstas últimas atan a los individuos en un lugar determinado de la escala social. A este respecto, los logros de un colectivo en ámbitos como la educación, la sanidad, la paz social o la seguridad en el empleo, afectarán indefectiblemente en las capacidades con que parten los sujetos que integran esos grupos ${ }^{4}$. Por ese motivo, las personas que crecen en contextos de pobreza asimilan casi por ósmosis esas "creencias caparazón" relativas a la inutilidad de aspectos como la educación o el empleo.

\section{LOS “FUNCIONAMIENTOS” COMO CLAVE DE LA POBREZA}

Para comprender mejor la operatividad de las creencias caparazón en la vida de las personas en situaciones de exclusión y pobreza resulta de gran utilidad acudir al concepto seniano de los "funcionamientos". Este concepto es presentado por Sen como respuesta al modelo de bienestar rawlsiano basado en la distribución de recursos o bienes primarios y al utilitarista de la satisfacción de deseos. Sen critica el modelo utilitarista del bienestar (wellfare) y en su lugar propone hablar de la calidad de vida (o wellbeing, bien-ser). El primero reduce el bienestar a la satisfacción de deseos; en cambio, el segundo (el bien-ser) concibe el bienestar en un sentido amplio, como la calidad de vida. Ésta no se limita a criterios subjetivos (las preferencias individuales) sino que incluye también factores como las oportunidades, libertades y capacidades con que cuenta el sujeto para desarrollar un plan de vida que pueda tener razones para valorar (Conill, 2004:

El informe de Cáritas La transmisión intergeneracional de la pobreza: factores, procesos y propuestas para la intervención, de 2016 resulta esclarecedor a este respecto. 
147). Por ello Sen defiende que se debe capacitar a la persona desde ámbitos como la educación, sanidad, servicios sociales, seguridad pública o seguridad en el empleo (Sen, 2000: 83). Sin estas condiciones las personas más desfavorecidas nunca podrán juzgar el tipo de vida que les gustaría vivir, sino que, al contrario, adaptarán sus deseos a lo que su entorno pone ante ellas (Sen, 1997: 62-63).

Pero la solución al problema tampoco vendrá por la distribución de recursos y bienes primarios como base de bienestar, como propone Rawls con su idea de los bienes primarios, entendidos como los medios que permiten a los sujetos alcanzar sus fines. Para Sen los bienes primarios son recursos generales cuyo uso está sujeto a las contingencias personales y sociales existentes entre las personas (Sen, 2000: 94-95). Por ese motivo, para analizar el bienestar debe partirse de la consideración de la vida real de las personas y la oportunidad que éstas tienen para realizar el plan de vida que tienen razones para valorar. Esto es así porque, y esta es una idea clave, la posibilidad que tienen los sujetos de traducir recursos en bienestar depende de sus condiciones reales de vida.

Aquí es donde Sen introduce su idea de "funcionamientos". Sen define este concepto como "las diversas cosas que una persona puede valorar hacer o ser" (Sen, 2000: 99). Dicho de una manera más concreta, qué cosas puede valorar, hacer o ser una persona con los recursos de que dispone (Sen, 1985: 10), o bien, qué tipo de vida conseguirá llevar a cabo con esos recursos. Las cosas que alguien puede valorar hacer o ser dependen de lo que uno necesita en la situación (personal, familiar y social) en que se encuentra; y lo que una persona necesita depende de lo que ha aprendido a valorar. Por ese motivo, en contextos sociales distintos, dos personas aprenderán a valorar de modo diferente. En consecuencia, tendrán necesidades distintas y ello las llevará a decidir hacer cosas muy distintas con unos mismos recursos. No se trata aquí de que las dos personas puedan desear hacer lo mismo, pero una pueda alcanzarlo y la otra no, sino que las cosas que las personas pueden valorar hacer pueden ser muy distintas dependiendo de la situación en que vivan y la libertad de agencia con la que cuenten. En este sentido un mismo recurso puede contribuir a realizar funcionamientos distintos. Esta concepción de los funcionamientos puede entenderse mejor recurriendo a la concepción orteguiana del valor.

Recordemos cómo Ortega (1964) criticaba tanto la concepción subjetivista del valor de Meinong como la objetivista de Ehrenfels. Frente a ambas Ortega proponía que los valores son cualidades irreales que están presentes en las cosas, pero que necesitan ser reconocidas (o estimadas) por la persona para que esos valores puedan hacerse patentes. Por ejemplo, hay personas que pueden reconocer la belleza de un cuadro abstracto, en cambio otras no están capacitadas para reconocer su valor y sólo ven 
en el lienzo garabatos que cualquiera podría trazar. Esto sucede porque para reconocer la belleza de un cuadro abstracto es necesario cultivar un sentido de la belleza estética que no todos los contextos sociales hacen posible. Pues bien, en un sentido similar, Sen afirma que determinados contextos limitan la capacidad de las personas para apreciar el valor de ciertas cosas. Esto sucede en contextos de pobreza y exclusión, en los que las personas puedan tener limitada su libertad de agencia, desarrollando preferencias adaptativas. Por ese motivo, Sen argumenta que debe capacitarse a las personas para que puedan elegir el plan de vida que les gustaría realizar; o en otras palabras, se las debe capacitar para que puedan reconocer el valor de ciertos elementos que de manera efectiva capacitan a las personas para elegir libremente un plan de vida.

Efectivamente, en esos contextos de miseria muchas personas son incapaces de reconocer el valor de ciertos elementos que pueden capacitarlas. Esto es debido al desarrollo de esas "creencias caparazón" que frenan la disonancia en momentos en que a priori debería aparecer. Un ejemplo claro es el de la educación. Es un hecho evidente que la educación capacita a las personas para tener unas mejores oportunidades de vida. Sin embargo, esto no es comprendido dentro de ciertos contextos de pobreza donde se desarrollan preferencias adaptativas. Allí simplemente no se reconoce el valor de la educación como elemento capacitador de la persona. Se percibe más bien como un estorbo que impide que los jóvenes colaboren con su trabajo para sacar a su familia adelante (Pereira, 2009: 61).

Esto explica el fracaso de las políticas sociales en su acción sobre esos grupos menos capacitados que, precisamente, son los que más necesitan de esos programas de ayudas. Es decir, los miembros de grupos sociales más vulnerables son los que menos se benefician de las políticas sociales, mientras que la clase media y alta hacen un mayor aprovechamiento de esos recursos. Este hecho es algo constatado no sólo por los liberales (Rallo, 2015), sino también por los estudios de Pereira y su equipo y el Grupo de Valencia sobre las preferencias adaptativas (Pereira, 2004; 2007; 2009; Fleitas, 2013; y especialmente Cortina \& Pereira, 2009). También los defensores de la renta básica (Van Parijs, 2002: 53; Pinilla, 2004: 67) inciden en este hecho. No en vano, uno de los argumentos que emplean para defender la renta básica es que esta medida constituye una forma de remediar este inconveniente presente en las ayudas sociales condicionadas. Los sujetos menos capacitados acaban quedando al margen de esos programas de ayudas condicionadas por desconocimiento, por desconfianza o por menor acceso a internet $u$ otros medios que les permitan estar informados de dichas ayudas. En cambio, como vimos al comienzo, la renta básica posee un carácter de incondicionalidad. Con ello la renta básica fija unas 
condiciones básicas de seguridad material que permite a los más necesitados tener un dominio sobre sus vidas.

Ahora bien, esta es sólo una parte del problema. En realidad, las políticas sociales fracasan también porque los diseñadores de dichas ayudas asumen una racionalidad abstracta, incapaz de reconocer la diversidad humana que Sen tanto se empeña en subrayar. Esta racionalidad calculadora que adoptan los elaboradores de las ayudas sociales se basa en la maximización del beneficio a partir de la asignación de un valor a todos los elementos que empoderan a las personas, como la educación. Dicho de otro modo, los técnicos, como personas que han desarrollado sus capacidades de un modo óptimo gracias a su formación en estudios superiores, presuponen que los perceptores de las ayudas también están capacitados paras valorar todos aquellos elementos que pueden empoderarlos, ya que les permitirían maximizar. Pero en realidad esto no es así, ya que muchos perceptores tienen mermada su libertad de agencia. En consecuencia, las políticas sociales fracasan porque quienes las elaboran y quienes las reciben razonan desde lógicas distintas.

A mi parecer, este prejuicio racionalista de presuponer que todas las personas están capacitadas que invade a los diseñadores de políticas sociales se explica en parte por la tendencia que todos tenemos de atribuir a las cosas propiedades funcionales. El funcionalismo enseña que las cosas tienen propiedades funcionales. Sin embargo, eso no es así: las cosas no tienen propiedades funcionales, pues las funciones que pueden desempeñar las cosas son múltiples (Stroud, 2003: 114). Por ejemplo, una "silla" no es "un mueble de cuatro patas, una base y un respaldo que sirve para sentarse". Porque la esencia de una cosa no incorpora el cumplir una función. Es decir, el sentarse no es el único uso que podemos dar a la silla. En realidad, el uso que damos a las cosas depende de nuestras necesidades en un contexto dado. Una silla nos sirve para sentarnos si estamos trabajando en la oficina o si necesitamos descansar. Pero resulta muy útil también para auparnos y coger un libro de una estantería, calentarnos con ella arrojándola a una hoguera o defendernos de un atacante.

Pues eso mismo sucede con la educación. Ésta por desgracia, carece de un valor autoevidente. El valor que le otorgan las personas depende del contexto en que viven, como hemos señalado arriba. Así, para cualquier persona que valora la educación, un libro contribuirá a realizar el funcionamiento de labrarse una vida mejor. En cambio, para una familia que no valora la educación, un libro producirá probablemente otro funcionamiento bien distinto: evitar el frío. En otras palabras, es probable que ésta segunda familia emplee los libros de texto de los hijos como combustible para la estufa. Esto, por cierto, no es algo que afirme a humo de pajas, sino que yo mismo fui testigo de ello. Esto le sucedido a una compañera de 
pupitre en el colegio público de un barrio deprimido en el que cursé la educación básica (E.G.B) ${ }^{5}$. Con este ejemplo deseo mostrar que un mismo recurso puede ser empleado para realizar funcionamientos distintos en contextos diferentes. Porque el valor que se atribuye a un objeto varía de un contexto a otro.

Por esa razón las capacidades colectivas adquieren una importancia esencial en el desarrollo de las capacidades de las personas. Quienes valoran la educación lo hacen, de manera general, porque han crecido en un contexto en el que la educación tenía un valor por su importancia para la capacitación personal y profesional. Estos sujetos tenían las necesidades básicas cubiertas, fueron escolarizados, había libros en casa, sus padres se preocuparon por que estudiaran, sus compañeros también estaban escolarizados, etc.... En consecuencia, desde ese contexto es complicado comprender lo difícil que resulta valorar la educación a personas que se han criado en contextos de marginalidad y exclusión ${ }^{6}$. Para que en contextos de pobreza las personas valoren la educación se tienen que dar unos condicionantes concretos: que su familia valore la educación, que quieran para sus hijos una vida mejor (algo nada sencillo entre quienes desarrollan preferencias adaptativas) y que se la puedan permitir (que no haya una situación de enfermedad de un adulto que obligue a los más pequeños a trabajar para traer dinero a casa), etc... Como el mismo Raventós reconoce, para captar el valor de ciertas cosas es necesario que algunas personas pasen antes por un proceso de capacitación ya que, de lo contrario, serán insensibles a ese valor (1999: 47). En este sentido, si queremos que los más pobres y necesitados que viven presos de las preferencias adaptativas valoren la educación, hay que actuar sobre los grupos en los que esos individuos conviven. Porque son esos grupos los que desarrollan entre sus miembros las actitudes que les impiden reconocer el valor de la educación.

5 Dicha experiencia pasada de niño quedó grabada en mi memoria, marcó mi interés posterior en la academia por profundizar en el estudio de las preferencias adaptativas y ha motivado la redacción de este trabajo.

$6 \quad$ Esta incapacidad de las personas que desconocen los contextos de exclusión para comprender las preferencias adaptativas es fruto de las diferencias cognitivas que separan a las personas. Pero esas diferencias cognitivas no deben confundirse con las que hemos denominado "creencias caparazón". Las primeras son fruto del choque entre ontologías morales distintas, e incapacitan a los sujetos para comprender la posición de otros sobre cuestiones políticas o morales (Pérez Zafrilla, 2017). En cambio, las creencias caparazón incapacitan a la persona no para comprender al otro, sino para ejercer su autonomía de forma efectiva para realizar la vida que tendría razones para valorar. 


\section{ACTUACIÓN PARA ERRADICAR LAS PREFERENCIAS ADAPTATIVAS}

Así pues, finalmente, ¿cómo es posible eliminar los efectos de las preferencias adaptativas convirtiendo a los sujetos que las padecen en seres plenamente autónomos y qué papel podría desempeñar la renta básica en ese proceso?

Las capacidades colectivas ponen de manifiesto que la acción para eliminar las preferencias adaptativas debe realizarse no directamente sobre los individuos, sino sobre los grupos, pues son estos los que enseñan a sus miembros a reconocer valor en ciertas cosas y no en otras. Como señala Pereira, el grupo es un elemento esencial tanto para la reproducción como para la reducción de la disonancia cognitiva entre sus miembros, blindando o desechando creencias y preferencias en sus miembros (Pereira, 2007: 148). En concreto, el objetivo de las acciones sociales a través de los grupos debe pasar por reforzar en los sujetos lo que Cortina denomina "agencia emocional" (Cortina, 2007: 214), es decir, la capacidad para controlar las emociones y modificarlas en el sentido correcto ${ }^{7}$. En otras palabras, la agencia emocional no es sino la capacidad que permite a las personas estimar las cosas necesarias para ser protagonista de su vida y dejar atrás esa falta de agencia ${ }^{8}$.

En este sentido, el modo de erradicar las preferencias adaptativas en los sujetos pasa por introducir elementos cognitivos que contradigan sus prácticas reproductivas de la pobreza. El equipo de Pereira ha analizado diferentes proyectos sociales y ha concluido que los que muestran una mayor eficacia son aquellos consistentes en un cierto modelo de ayudas condicionadas ${ }^{9}$. Se trata de ayudas condicionadas al compromiso de las familias a invertir en capital humano, especialmente la educación infantil. Estos programas consisten en una transferencia de ingresos unida a proyectos dirigidos a la promoción de ciertas acciones que buscan fortalecer la agencia de los beneficiarios. Son además proyectos de desarrollo vinculados al

\footnotetext{
7 Esta agencia emocional es clave para diferenciar entre las preferencias adaptativas y la planificación del carácter. En ésta el sujeto es capaz de controlar su disonancia cognitiva asimilando la información y modificando sus actitudes para actuar del modo adecuado. En cambio, las preferencias adaptativas son consecuencia de la incapacidad del sujeto para controlar sus emociones cuando se produce la disonancia cognitiva. De ahí que se deje llevar por sesgos cognitivos como el de razonamiento motivado.

8 Sin ese primer paso de empoderamiento emocional para reconocer lo valioso, el resto de medidas dirigidas a la distribución de medios caerán en saco roto.

9 Programas de este tipo se han desarrollado en diferentes países de Hispanoamérica, como México (Progresa/Oportunidades), Colombia (Familias en Acción) o Uruguay (PANES), entre otros.
} 
contexto y las capacidades de sus receptores ${ }^{10}$. En general estos proyectos pretenden promover la agencia de los sujetos con preferencias adaptativas poniendo a estos en contacto con otros grupos de personas que gozan de un pleno desarrollo de las capacidades. Ese contacto producido, por ejemplo, a través de la escolarización o la inserción laboral, permite a las personas menos capacitadas aprender nuevos horizontes vitales más ricos en los que poder realizarse ellas también. Así este contacto permitirá a los sujetos reforzar su agencia emocional. Ello les posibilitará también reconocer su situación de autonomía mermada y evaluar positivamente otras alternativas vitales más prometedoras. Con ello los sujetos adoptarán muevas actitudes emancipatorias que les permitan sacar provecho de esa transferencia de ingresos (Amarante, Arim \& Perazzo, 2009: 263-280).

Esta dinámica de promoción de la persona, generación de nuevas perspectivas que llevan al desarrollo de la agencia y transferencias condicionadas será clave para la erradicación de las preferencias adaptativas. Ciertamente, a corto plazo el contacto de los sujetos con preferencias adaptativas con personas capacitadas les hace a los primeros conscientes de su autonomía mermada. Esto les introduce una mayor disonancia que podría llevarles a abandonar esos entornos de realización personal y buscar su zona de confort entre la miseria. Para evitar ese retorno se introducen precisamente las prestaciones condicionadas, que les permitan contar con una base económica que les capacite para afrontar ese nuevo entorno. La prestación económica ejerce como compensación de bienestar que mitigue la aparición de la disonancia cognitiva y permita a los sujetos progresar en el fortalecimiento de su agencia (Pereira, 2009: 62).

Pues bien, los ejes de estos programas pueden sentar las bases para que las personas que viven en condiciones de miseria puedan hacer un uso fructífero de la renta básica. El empoderamiento de las personas debe empezar con el grupo, enseñando al colectivo a promover el desarrollo de las capacidades entre sus miembros. En cambio, limitarse a la distribución de la renta básica presupone una capacitación previa de los sujetos para hacer uso autónomo de los recursos suministrados. Ello claramente olvida el papel que desempeña el grupo en el desarrollo personal, y de ahí el fracaso de la renta básica entre quienes viven en condiciones de extrema necesidad, como reconoce el mismo Raventós, al carecer dichas personas de un desarrollo mínimo de las capacidades (Raventós, 1999: 47).

10 Esta es una idea clave, señalada por autores como Goulet (1999), Conill (2009), Martínez Navarro (2000) o Cortina (2017): ni el desarrollo ni la economía pueden abordarse sin tener en cuenta el contexto donde los diferentes programas se van a aplicar. Por eso Conill propone una "economía hermenéutica" (2009: 151-162), atenta a las circunstancias y las necesidades reales de las personas. De lo contrario sucederá que los programas diseñados serán por completo ineficientes. 
En esta línea, el empoderamiento de los más pobres no puede conseguirse por la mera distribución de recursos porque la renta básica sólo puede capacitar a la persona para hacer algo que previamente ha aprendido a estimar pero que por su situación de pobreza no puede lograr. Un ejemplo claro es la escolarización. Pinilla afirma que la renta básica permitirá a las personas dedicar tiempo a estudiar (2004: 62). Pero, a la luz de lo defendido hasta ahora, podemos concluir que dedicarán más tiempo al estudio si previamente valoran la educación. De lo contrario, la renta básica la emplearán para otras cosas que los sujetos valoren. Es decir, la renta básica proporciona a los sujetos una red de seguridad económica que les permite elegir con libertad entre aquellas cosas que previamente valoraban. Pero la renta básica por sí misma no le hará valorar cosas que previamente no ha aprendido a estimar en su grupo de pertenencia. Como señala Pereira, una distribución igual de medios lleva a sostener a Van Parijs que la justicia se ha alcanzado. Pero, continúa Pereira, esto deja sin considerar otros factores sociales que pesan en las elecciones personales, como afirma Sen (Pereira, 2010: 141).

De hecho, algunos defensores de la renta básica reconocen que esta medida sólo puede tener un poder emancipatorio real si va acompañada de un conjunto de medidas sociales complementarias en ámbitos como el desempleo, sanidad, dependencia y educación que garanticen a los menos aventajados el pleno ejercicio de la autonomía (Casassas \& De Wispeleare, 2011: 105-136). Como apuntan Casassas y De Wispeleare, si aceptamos que la renta básica empodera por sí misma a la persona, en pura lógica cuanto mayor sea el importe de la renta básica más se podrá empoderar a la persona. Es decir, una renta básica de $3.000 €$ capacitaría más que una de $500 €$. Pero entonces, alguien podría proponer desmantelar los sistemas de sanidad, dependencia y educación pública y dedicar esos impuestos a costear esa renta básica tan cuantiosa que, de este modo, otorgara mayor libertad a las personas ${ }^{11}$. Pero en este caso las personas menos capacitadas podrían encontrarse con que los seguros privados exigieran precios prohibitivos para cubrir ciertas prestaciones vitales. Esto haría a esas personas menos capacitadas quedar desprotegidas aun contando con una renta básica bastante cuantiosa y que no pudieran cubrir esas prestaciones.

Así pues, podemos concluir que la renta básica no es útil por sí misma para capacitar a los sujetos que viven en condiciones de pobreza. La renta básica sólo podrá ser útil para los más pobres una vez que esas personas necesitadas hayan desarrollado sus capacidades gracias a otro tipo de medidas que permitan dejar atrás los contextos de preferencias adaptativas.

\footnotetext{
11 Esto convertiría a la renta básica en una medida similar al denominado "cheque escolar".
} 


\section{CONCLUSIÓN}

Como hemos señalado a lo largo del trabajo, la renta básica es una propuesta emancipadora de la ciudadanía al otorgar a ésta una base económica con la que poder afrontar la vida con más coraje. De esta forma, la seguridad económica permitiría a los individuos realizar el plan de vida que realmente tiene razones para valorar. Sin embargo, la existencia de las preferencias adaptativas en contextos de pobreza o marginación merman esa capacidad de empoderamiento que se atribuye a la renta básica justamente entre los colectivos que, en teoría, más se tendrían que ver beneficiados por ella.

En este sentido, podemos concluir señalando que la renta básica podrá contribuir a la eliminación de la pobreza si va acompañada de otras políticas que desarrollen las capacidades de las personas, y, de una manera especial, la educación de la agencia emocional de los individuos. Esa agencia emocional es la que permite a los sujetos estimar los elementos emancipatorios como la educación o el empleo, que les permitan dejar atrás las preferencias adaptativas. Sólo así, desde la plena autonomía para poder conducir sus vidas hacia su empoderamiento, los sujetos menos aventajados, y más necesitados, serán capaces de sacar el provecho posible a la distribución de esa renta básica.

\section{REFERENCIAS}

Amarante, V., Arim, R. \& Perazzo, I. (2009). El impacto de las políticas para la reducción de la pobreza sobre la agencia. En A. Cortina y G. Pereira. (Eds.), Pobreza y libertad. Erradicar la pobreza desde el enfoque de las capacidades de Amartya Sen (pp. 263-280). Madrid, Tecnos.

Burdin, G., Leites, M., Salas, G. \& Vigorito, A. (2009). Agencia, pobreza y bienestar. Una propuesta para su operacionalización. En A. Cortina y G. Pereira (Eds.), Pobreza y libertad. Erradicar la pobreza desde el enfoque de las capacidades de Amartya Sen (pp. 163-192). Madrid: Tecnos.

Cáritas. (2016). La transmisión intergeneracional de la pobreza: factores, procesos y propuestas para la intervención. Madrid: Fundación FOESSA.

Casassas, D. \& De Wispeleare, J. (2011). Renta básica y emancipación social: principios, diseños y coaliciones. En David Cassasas y Daniel Raventós (Eds.), La renta básica en la era de las grandes desigualdades (pp. 105-136). Barcelona: Montesinos.

Conill, J. (2004) Horizontes de economía ética. Aristóteles, Adam Smith, Amartya Sen. Madrid: Tecnos.

Conill, J. (2009). Por una economía hermenéutica de la pobreza. En A. Cortina y G. Pereira (Eds.), Pobreza y libertad. Erradicar la pobreza desde el enfoque de las capacidades de Amartya Sen (pp. 151-162). Madrid: Tecnos, 
Cortina, A. (2001). Ciudadanía económica cosmopolita. El País, 5 de junio.

Cortina, A. (2007). Ética de la razón cordial. Oviedo: Nobel.

Cortina, A. (2009). Pobreza como falta de libertad. En A. Cortina y G. Pereira (Eds.), Pobreza y libertad. Erradicar la pobreza desde el enfoque de las capacidades de Amartya Sen (pp. 15-30). Madrid: Tecnos.

Cortina, A. (2013). ¿Para qué sirve realmente la ética? Barcelona: Paidós.

Cortina, A. (2017). Aporofobia, el rechazo al pobre. Un desafí para la democracia. Barcelona: Paidós.

Cortina, A. \& Pereira, G. (Eds.) (2009). Pobreza y libertad. Erradicar la pobreza desde el enfoque de las capacidades de Amartya Sen. Madrid: Tecnos.

Doménech, A. (2003). El eclipse de la fraternidad. Una revisión republicana de la tradición socialista. Barcelona: Crítica.

Esopo (2000). Fábulas. Madrid: Gredos.

Elster, J. (1988). Uvas amargas. Sobre la subversión de la racionalidad. Barcelona: Península.

Evans, P. (2002). Collective capabilities, culture and Amartya Sen's Development as freedom. Studies in Comparative International Development, 37(2), 54-60.

Fleitas, M. (2013) Sobre las preferencias adaptativas y la subversión de la personalidad. Sistema, (232), 75-92.

Frankman, M. J. (2004). World Democratic Federalism: Peace and Justice Indivisible. Houndmills, Basingstoke \& New York: Palgrave-Macmillan.

Goulet, D. (1999). Ética del desarrollo. Guía teórica y práctica. Madrid: Colección Cooperación y Desarrollo.

Haidt, J. (2001). The emotional dog and its rational tail. A social intuitionist approach to moral judgement, Psychological Review, 108(4), 814-834.

Haidt, J. \& Bjorklund, F. (2008). Social Intuitionists answer six questions about moral psychology. En W. Sinnott-Armstrong (Ed.). Moral Psychology (vol. 2, pp. 181-207). Massachusetts: The MIT Press.

Kunda, Z. (1990). The case for motivated reasoning. Psychological Bulletin, 108(3), 480-498.

Martínez Navarro, E (2000). Ética para el desarrollo de los pueblos. Madrid: Trotta.

Mercier, H. \& Sperber, D. (2011). Why do humans reason? Arguments for an argumentative theory? Behavioural and brain sciences, 34(2), 57-111.

Nussbaum, M. (2002). Las mujeres y el desarrollo bumano. Barcelona: Herder.

Ortega y Gasset, J. (1964). Introducción a una estimativa. Qué son los valores. Obras Completas. (Vol. VI, pp. 315-335). Madrid: Revista de Occidente.

Pedrajas, M. (2006). El desarrollo bumano en la economia ética de Amartya Sen. Valencia: Universitat de Valencia.

Pereira, G. (2004). Autonomía, preferencias adaptativas y políticas públicas. Sistema, (178), 71-85.

Pereira, G. (2007). Preferencias adaptativas: un desafío para el diseño de las políticas públicas. Isegoría. Revista de Filosofía Moral y Política, (36), 143-165.

Pereira, G. (2009) Preferencias adaptativas como bloqueo de la autonomía. En A. Cortina y Gustavo Pereira (Eds.), Pobreza y libertad. Erradicar la pobreza desde el enfoque de las capacidades de Amartya Sen (pp.57-76). Madrid: Tecnos. 
Pereira, G. (2010). Las voces de la igualdad. Bases para una teoría crítica de la justicia. Cànoves i Salamús: Proteus.

Pérez Zafrilla, P. J. (2013). Implicaciones normativas de la psicología moral: Jonathan Haidt y el desconcierto moral. Daimon. Revista Internacional de Filosofía, (59), 9-25.

Pérez Zafrilla, P. J. (2016). Is Deliberative Democracy an adaptive political theory? A critical analysis of Hugo Mercier's Argumentative Theory of Reasoning. Análise Social, (220), 544-564.

Pérez Zafrilla, P. J. (2017). Por qué fracasa la deliberación y cómo podemos remediarlo. Una alternativa ética al enfoque neurocientífico. Daimon. Revista Internacional de Filosofía, (70), 131-146.

Pinilla, R. (2004). La renta básica de ciudadanía. Una propuesta clave para la renovación del Estado del bienestar. Barcelona: Icaria.

Pogge, T. (1994). An Egalitarian Law of Peoples. Philosophy and Public Affairs, 23(3), 195-224.

Rallo, J. R. (2015). Contra la renta básica. Por qué la redistribución de la renta restringe nuestras libertades y nos empobrece a todos. Madrid: Deusto.

Rallo, J. R. (2017). Libertarianism and Basic-Income Guarantee: Friends or Foes? Journal of Business Ethics. Disponible en https://link.springer.com/article/10.1007\%2Fs10551-017-3645-9

Rawls, J. (1996). Liberalismo político. Barcelona: Crítica.

Raventós, D. (1999). El derecho a la existencia. La propuesta del Subsidio Universal Garantizado. Barcelona: Ariel.

Raventós, D. (2002). La renta básica: Introito. En D. Raventós (Coord.). La renta básica. Por una ciudadanía más libre, más igualitaria y más fraterna (pp. 21-41). Barcelona: Ariel.

Raventós, D. (2007). Las condiciones materiales de la libertad. Barcelona: Ediciones de Intervención Cultural.

Reyes Morel, A. (2009). Comunidades de significación como capacidades colectivas. Una revisión comunitarista de Amartya Sen. En A. Cortina y G. Pereira (Eds.), Pobreza y libertad. Erradicar la pobreza desde el enfoque de las capacidades de Amartya Sen (pp. 33-55). Madrid: Tecnos.

Sen, A. (1985). Commodities and capabilities. Amsterdam: Nort-Holland.

Sen, A. (1995). Nuevo examen de la desigualdad. Madrid: Alianza.

Sen, A. (1997). Sobre ética y economía. Madrid: Alianza.

Sen, A. (2000). Desarrollo y libertad. Barcelona: Planeta.

Sibley, W. M. (1953). The rational Versus the Reasonable. Philosophical Review, 62(4), 554-560.

Stroud, B. (2003). La búsqueda de la realidad: el subjetivismo y la metafísica del color. Madrid: Síntesis.

Taylor, C. (1996). Las fuentes del yo. La construcción de la identidad moderna. Barcelona: Paidós.

Van Parijs, P. (1996). Libertad real para todos. Qué puede justificar el liberalismo (si hay algo que pueda hacerlo). Barcelona: Paidós. 
Van Parijs, P. (2002). Una renta básica para todos. En D. Raventós (Coord.), La renta básica. Por una ciudadanía más libre, más igualitaria y más fraterna. (pp. 4361). Barcelona: Ariel.

Van Parijs, P. \& Vanderborght, Y. (2001). From Euro-Stipendium to Euro-Dividend. Journal of European Social Policy, 11(4), 342-346.

Van Parijs, P. \& Vanderborght, Y. (2010). Basic Income, Globalization and Migration. Versión revisada del paper presentado en: Sustainable Utopia and Basic Income in Global Era, Proceedings of the Basic Income International Conference, 27-28 de enero. Disponible en https://cdn.uclouvain.be/public/Exports $\% 20$ reddot/etes/documents/2010.BIGlobalizationMigrationdraft4.pdf

Zwlinski, M. (2015). Property Rights, Coercion, and the Welfare State. The Libertarian Case for Basic Income for All. The Independent Review, 19(1), 515-529.

Sumario: Introducción; 1. La renta básica; 2. La racionalidad y las preferencias adaptativas; 3. La planificación del carácter y las preferencias adaptativas; 4. Las "creencias caparazón"; 5. Los "funcionamientos" como clave de la pobreza; 6. Actuación para erradicar las preferencias adaptativas; Conclusión; Referencias. 